\title{
The traditional Chinese medical compound Rocaglamide protects nonmalignant primary cells from DNA damage-induced toxicity by inhibition of p53 expression
}

\author{
MS Becker ${ }^{1}$, P Schmezer ${ }^{2}$, R Breuer ${ }^{1}$, SF Haas ${ }^{3}$, MA Essers ${ }^{3}$, PH Krammer ${ }^{1}$ and M Li-Weber ${ }^{\star, 1}$
}

One of the main obstacles of conventional anticancer therapy is the toxicity of chemotherapeutics to normal tissues. So far, clinical approaches that aim to specifically reduce chemotherapy-mediated toxicities are rare. Recently, a number of studies have demonstrated that herbal extracts derived from traditional Chinese medicine (TCM) may reduce chemotherapy-induced side effects. Thus, we screened a panel of published cancer-inhibiting TCM compounds for their chemoprotective potential and identified the phytochemical Rocaglamide (Roc-A) as a candidate. We show that Roc-A significantly reduces apoptotic cell death induced by DNA-damaging anticancer drugs in primary human and murine cells. Investigation of the molecular mechanism of Roc-A-mediated protection revealed that Roc-A specifically blocks DNA damage-induced upregulation of the transcription factor p53 by inhibiting its protein synthesis. The essential role of p53 in Roc-A-mediated protection was confirmed by siRNA knockdown of p53 and by comparison of the effects of Roc-A on chemoprotection of splenocytes isolated from wild-type and p53-deficient mice. Importantly, Roc-A did not protect p53-deficient or -mutated cancer cells. Our data suggest that Roc-A may be used as an adjuvant to reduce the side effects of chemotherapy in patients with p53-deficient or -mutated tumors.

Cell Death and Disease (2014) 5, e1000; doi:10.1038/cddis.2013.528; published online 16 January 2014

Subject Category: Cancer

'Classic' genotoxic anticancer drugs all target DNA. ${ }^{1}$ DNAdamaging agents are potent inducers of cell death by triggering apoptosis not only in cancer but also in normal tissues. Especially, the toxicity to the hematopoietic system is the main challenge in anticancer treatment, as a decrease in white blood cell counts is usually the dose-limiting factor., ${ }^{2,3}$ Reduction in leukocytes causes weakening of the immune system and, thus, often leads to the development of opportunistic infections that in the worst case can result in death of the patient. ${ }^{4,5}$ Nevertheless, induction of DNA damage, such as DNA double-strand breaks (DSBs), has been shown to be an effective treatment of cancer. ${ }^{6}$ In fact, most currently used anticancer drugs, for example, Etoposide, Bleomycin, Doxorubicin, Teniposide and so on, act by causing DNA damage. ${ }^{6}$ Taken together, there is an urgent need for new therapeutic strategies that can reduce the toxicity of treatment on normal tissues but still maintain efficacy against the tumor.

Natural products are an important source of drugs in medicine. Recently, several studies showed that herbal extracts from traditional Chinese medicine (TCM) could reduce chemotherapy-induced side effects in vivo. ${ }^{7-10}$
For instance, the herbal mixture PHY906, which is based on the TCM Huang Qin Tang, reduced CPT-11-induced toxicity in mice, ${ }^{10}$ a finding that is further supported by a phase $1 / 2$ clinical trial. ${ }^{11}$ Other clinical studies suggest that Chinese herbal extracts may reduce the chemotherapy-induced decrease in white blood cell counts. ${ }^{12}$ These results prompted us to investigate TCM compounds that could protect normal tissues from DNA damage-induced cell death.

In this study, we screened a panel of known cancerinhibiting TCM compounds for their chemoprotective potential and found that Rocaglamide (Roc-A) reduces DNA damageinduced apoptosis in nonmalignant primary cells. Roc-A belongs to a group of phytochemicals, characterized by a cyclopenta[$[b]$-tetrahydrobenzofuran backbone, collectively named rocaglamides that are isolated from the TCM plant Aglaia. ${ }^{13-15}$ Roc-A and its derivatives have been shown to possess anticancer activities in vitro in various tumor cell lines and patient samples and to inhibit tumor growth in vivo in several mouse tumor models. ${ }^{14,15}$ The primary effect of rocaglamides on tumor growth inhibition was shown to be caused by inhibition of protein synthesis. ${ }^{16,17}$ Two mechanisms, which ultimately lead to inactivation of the mRNA

\footnotetext{
${ }^{1}$ Tumorimmunology Program (D030), German Cancer Research Center (DKFZ), INF-280, D-69120 Heidelberg, Germany; ${ }^{2}$ Division of Epigenomics and Cancer Risk Factors, German Cancer Research Centre (DKFZ), INF-280, D-69120 Heidelberg, Germany and ${ }^{3}$ Division of Stem Cells and Cancer, German Cancer Research Center (DKFZ), Heidelberg, Germany

*Corresponding author: M Li-Weber, Tumor Immunology Program D030, German Cancer Research Center (DKFZ), Im Neuenheimer Feld 280,69120 Heidelberg, Germany. Tel: +49 6221 423748; Fax: +49 6221 411715; E-mail: m.li-weber@dkfz-heidelberg.de

Keywords: chemoprotection; p53; apoptosis; Rocaglamide; anticancer drug; TCM

Abbreviations: DSB, DNA double-strand break; SSB, DNA single-strand break; HSPCs, hematopoietic stem and progenitor cell; Roc-A, Rocaglamide; TCM, traditional Chinese medicine; CHX, cycloheximide; KO, knockout; WT, wild type

Received 23.9.13; revised 26.11.13; accepted 27.11.13; Edited by A Stephanou
} 
cap-binding eukaryotic translation initiation factor elF4E and the translation initiation factor elF4A, result in inhibition of protein synthesis. ${ }^{18,19}$

We further investigated the molecular mechanisms by which Roc-A protects normal cells from DNA damage-induced cell death and revealed that the transcription factor p53 is essential for this protection. It is well known that p53 plays an important role in the DNA damage response by inducing the expression of DNA repair proteins and also of genes involved in apoptosis, for example, BBC3 (PUMA) and BAX. When DNA damage exceeds a certain threshold and DNA repair fails, damaged cells undergo apoptosis. ${ }^{1,20}$ We show that Roc-A prevents DNA damage-induced apoptosis in normal cells by inhibition of p53 expression at the translational level. Importantly, p53-deficient and mutant tumor cells are not protected by Roc-A from DNA damage-induced cell death.

\section{Results}

Roc-A protects nonmalignant cells against DNA damage-induced cytotoxicity. To identify TCM compounds that can protect nontransformed primary cells from DNA damage-induced cytotoxicity, we performed a cell viability screen. Human peripheral blood $T$ lymphocytes ( $T$ cells) from healthy donors were used as a model cell for healthy tissue. $T$ cells were treated with the genotoxic chemotherapeutic drug Etoposide in the absence or presence of different TCM compounds. After $24 \mathrm{~h}$ of treatment, cell viability was determined by the Cell-Titer Glo viability assay (Promega, Mannheim, Germany). Among the analyzed compounds, Roc-A showed the strongest chemoprotective effect on $\mathrm{T}$ cells by reducing Etoposide-induced cytotoxicity by more than twofold (Figure 1a). Therefore, we focused on Roc-A for further analysis.

To validate the screening results, we treated normal $\mathrm{T}$ cells with increasing concentrations of Etoposide with or without different concentrations of Roc-A. After $24 \mathrm{~h}$ of treatment, apoptotic cell death was measured by specific DNA fragmentation, AnnexinV staining or determination of apoptotic-like changes in cell size and cellular granularity (FSC/SSC profile). The experiments showed that Etoposide treatment caused cell death of normal $T$ cells that was reduced in the presence of Roc-A in a dose-dependent manner to $>50 \%$ (Figure $1 \mathrm{~b}$, left panel and Supplementary Figure S1). Kinetic analysis showed that Roc-A could reduce the toxicity of Etoposide at all measured time points (Figure 1b, middle panel). Strikingly, the chemoprotective effect could be even seen when Roc-A was administered after several hours of Etoposide treatment (Figure 1b, right panel).

To investigate whether Roc-A could also protect normal cells from cell death induced by other DNA damaging anticancer drugs, we treated $T$ cells with increasing doses of Teniposide, Doxorubicin and Bleomycin in the presence or absence of Roc-A. The experiment showed that Roc-A could reduce drug-induced apoptosis in all cases (Figure 1c).

Next, we asked whether Roc-A could also protect other normal primary cells from DNA damage-induced toxicity. To address this question, we examined the protective effect of Roc-A on Etoposide-treated human peripheral blood B cells, NK cells, neutrophils, cardiomyocytes and murine hematopoietic stem and progenitor cells (HSPCs). The experiments revealed that all examined cells were protected by Roc-A against Etoposide-induced apoptosis (Figure 1d). Taken together, these data indicate that Roc-A can protect primary nonmalignant cells from DNA damage-induced cytotoxicity.

Roc-A exerts its protection downstream of DNA damage. Genotoxins such as Etoposide induce apoptosis mainly through induction of DNA damage. ${ }^{21}$ We therefore asked whether Roc-A could prevent genotoxin-induced DNA damage and thereby reduces genotoxin-induced cell death. To address this question, we determined the level of the DNA-damage marker $\gamma-\mathrm{H} 2 \mathrm{AX}$ that is generated around the site of a DNA DSB. ${ }^{22}$ Etoposide treatment resulted in an increase in $\gamma-\mathrm{H} 2 \mathrm{AX}$ foci formation in a concentration- and time-dependent manner (Figures $2 a$ and b). A maximum amount of $\gamma-\mathrm{H} 2 \mathrm{AX}$ foci formation was observed at $4 \mathrm{~h}$ after treatment (Figure 2b). However, Roc-A did not block Etoposide-induced $\gamma-\mathrm{H} 2 \mathrm{AX}$ foci formation (Figures $2 \mathrm{a}-\mathrm{c}$ ). Similar results were obtained by alkaline single-cell gel electrophoresis assay (Comet assay) that detects both DNA single-strand breaks (SSBs) and DSBs (Figure 2d and e). Therefore, the protective effect of Roc-A appears to be downstream of DNA damage.

Roc-A inhibits DNA damage-induced increase in p53 expression. The transcription factor p53 is a major regulator of DNA damage-induced apoptosis. ${ }^{23}$ Therefore, we investigated the effect of Roc-A on the expression level of p53. $\mathrm{T}$ cells were treated with increasing concentrations of Etoposide in the presence or absence of Roc-A and p53 protein expression was analyzed by immunoblot. The experiment showed that Etoposide treatment increased p53 protein levels. However, in the presence of Roc-A, p53 expression was blocked in a dose-dependent manner (Figure 3a). Roc-A-mediated suppression of p53 upregulation was not specific for Etoposide, as inhibition was also observed in Bleomycin-, Teniposide- and Doxorubicin-treated cells (Figure 3b). Kinetic analysis showed that the increase in p53 protein levels could be detected as early as $4 \mathrm{~h}$ after Etoposide treatment and reached the highest level at $24 \mathrm{~h}$ (Figure 3c and Supplementary Figure S2). Roc-A could inhibit upregulation of p53 at all time points analyzed (Figure $3 c$ ). The time of p53 upregulation coincided with the onset of apoptosis induction (Figure 1b). To ensure that Roc-A-mediated suppression of p53 upregulation was not only specific for $\mathrm{T}$ cells, the effect of Roc-A on p53 expression was also examined in $\mathrm{B}$ and NK cells treated with Etoposide. Consistent with the results obtained for $\mathrm{T}$ cells, Etoposide-induced p53 increase in B and NK cells was also suppressed by Roc-A (Figures $3 d$ and e). These data indicate that Roc-A might protect normal tissue from DNA damage-induced apoptosis by downregulation of genotoxin-induced p53 expression.

p53 plays an essential role in Roc-A-mediated protection. To investigate the role of p53 in Roc-A-mediated protection of normal tissue, we induced p53 upregulation without the induction of DNA damage. To do so, T cells were treated with 
a

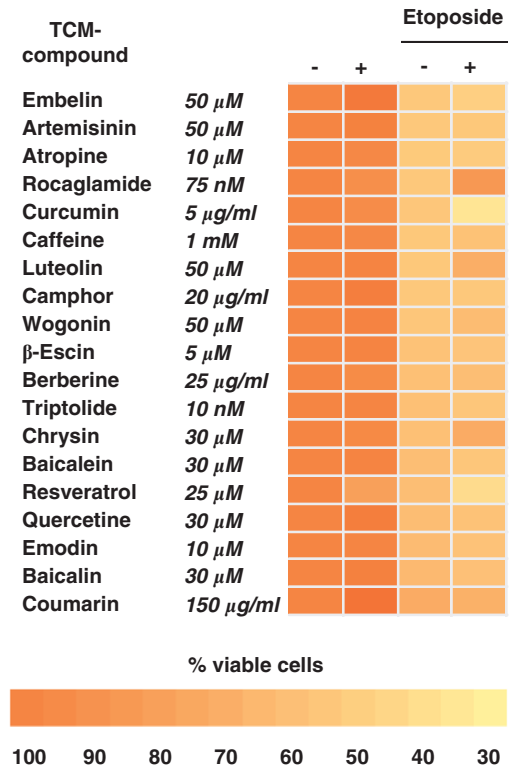

b $\rightarrow$ DMSO

ㅁ. Roc-A $25 \mathrm{nM}$

- Roc-A $50 \mathrm{nM}$

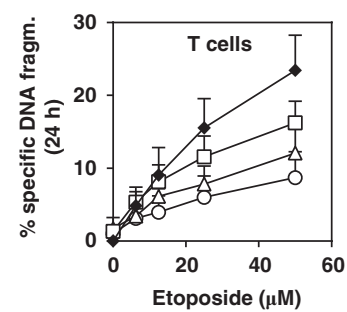

C

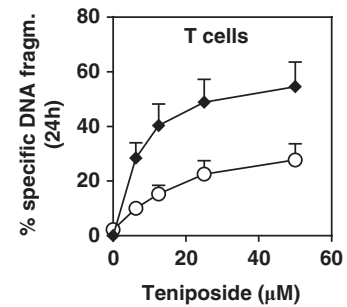

- Etoposide + DMSO

ㄴ Etoposide + Roc-A $25 \mathrm{nM}$

$\triangle-$ Etoposide + Roc-A $50 \mathrm{nM}$

- - Etoposide + Roc-A 75 nM
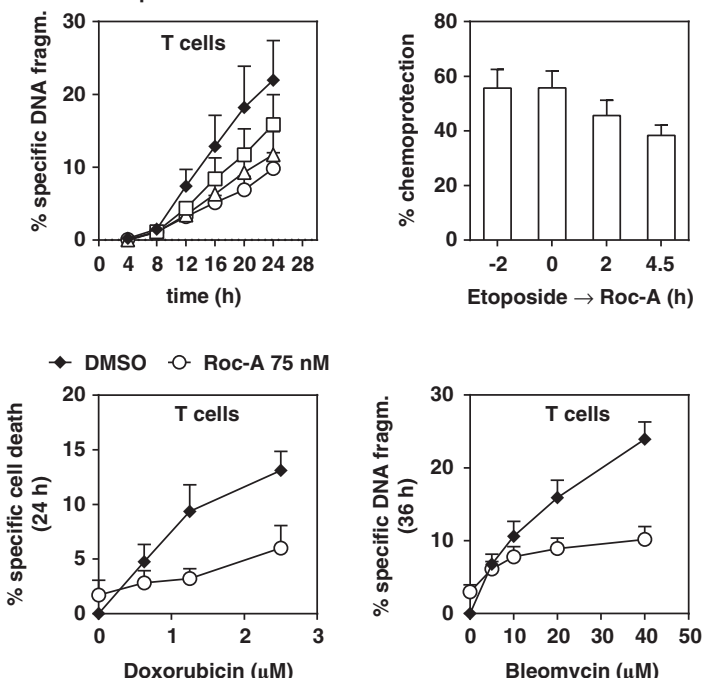

d

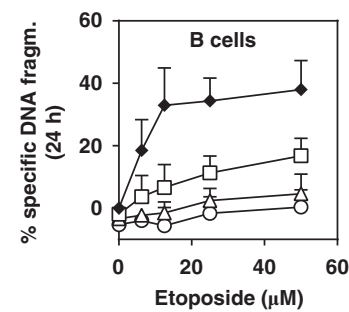

- DMSO $\square$ Roc-A 25 nM $\triangleleft$ Roc-A 50 nM -O Roc-A 75 nM


Figure 1 Roc-A protects nonmalignant cells from DNA damage-induced cytotoxicity. (a) A cell viability screen reveals Roc-A to be a potential DNA damage-protective compound. Peripheral blood T cells from healthy donors were treated with solvent (DMSO) or $50 \mu \mathrm{M}$ Etoposide in the presence of different TCM compounds or solvent as indicated. Cell viability was determined after $24 \mathrm{~h}$ of treatment by Cell-Titer Glo viability assay. Data are an average of three independent experiments. (b) Roc-A protects T cells from Etoposide-induced cell death in a dose- and time-dependent manner. Left panel: T cells were treated with solvent (DMSO) or increasing amounts of Etoposide in the presence of different concentrations of Roc-A or solvent (DMSO) for $24 \mathrm{~h}$. Cell death was determined by DNA fragmentation. Data are an average of three independent experiments. Error bars (S.D.) are shown. Middle panel: T cells were treated with $50 \mu \mathrm{M}$ Etoposide in the presence of different concentrations of Roc-A or solvent (DMSO) for the indicated time periods. Cell death was determined by DNA fragmentation. Data are an average of three independent experiments. Error bars (S.E.M.) are shown. Right panel: Roc-A was added $2 \mathrm{~h}$ before, in parallel or 2 and $4.5 \mathrm{~h}$ after Etoposide $(50 \mu \mathrm{M})$ treatment. Data are presented as percent of protection of T cells from Etoposide-induced cell death. Results are an average of three independent experiments. Error bars (S.E.M.) are shown. (c) Roc-A reduces Teniposide-, Doxorubicin- and Bleomycin-induced cell death in T cells. Peripheral blood T cells were treated with Teniposide (left panel), Doxorubicin (middle panel), Bleomycin (right panel) or solvent (DMSO) in the presence of Roc-A $(75 \mathrm{nM})$ or solvent (DMSO) as indicated. Cell death was determined by DNA fragmentation for Teniposide and Bleomycin treatment or by FSC/SSC profile for Doxorubicin treatment. Data are an average of three independent experiments. Error bars (S.D.) are shown. (d) Roc-A protects a panel of nontransformed primary cells from Etoposide-induced cell death. Primary human B cells, NK cells, neutrophils, HSPCs and cardiomyocytes were treated with solvent (DMSO) or Etoposide in the presence of different concentrations of Roc-A or solvent (DMSO) for different times as indicated. Cell death was determined by DNA fragmentation. Results are an average of three to four independent experiments. Error bars (S.D.) are shown

Nutlin-3 which has been shown to increase $\mathrm{p} 53$ protein levels by preventing Mdm2-mediated 553 degradation. ${ }^{24}$ This experiment showed that Roc-A could also inhibit Nutlin-3induced p53 upregulation and, consequently, cell death (Figure 4a). Thus, Roc-A does not solely affect DNA damage-induced cell death, but may in general affect p53mediated cell death. This assumption was supported by analysis of p53 target genes that are involved in apoptosis regulation. For instance, Etoposide-induced increase in $B A X$, $M D M 2, B B C 3$ (PUMA) and FAS mRNA expression was blocked in the presence of Roc-A (Figure 4b). As a control, the mRNA level of BCL2L11 (BIM), whose expression is not regulated by $\mathrm{p} 53,{ }^{25}$ was shown not to be considerably affected by Roc-A (Figure 4b).
To further investigate the role of p53 in Roc-A-mediated protection of T cells against DNA damage-induced apoptosis, we performed a p53-knockdown experiment using two siRNAs directed against p53 which yielded similar results (Figure 4c, upper panel, data are only shown for one siRNA). The experiment showed that downregulation of p53 protein levels in T cells (Figure 4c, upper panel, lane 7) rendered the cells more resistant to Etoposide and reduced cell death to a level similar to Roc-A treatment (Figure 4c, lower panel). As the siRNA-mediated p53 knockdown could not fully block p53 expression (Figure 4c, upper panel, lane 7), Roc-A could still further downregulate the expression of p53 in p53-knockdown cells (Figure 4c, upper panel, lane 8). Consequently, Roc-A was still able to protect p53-knockdown 

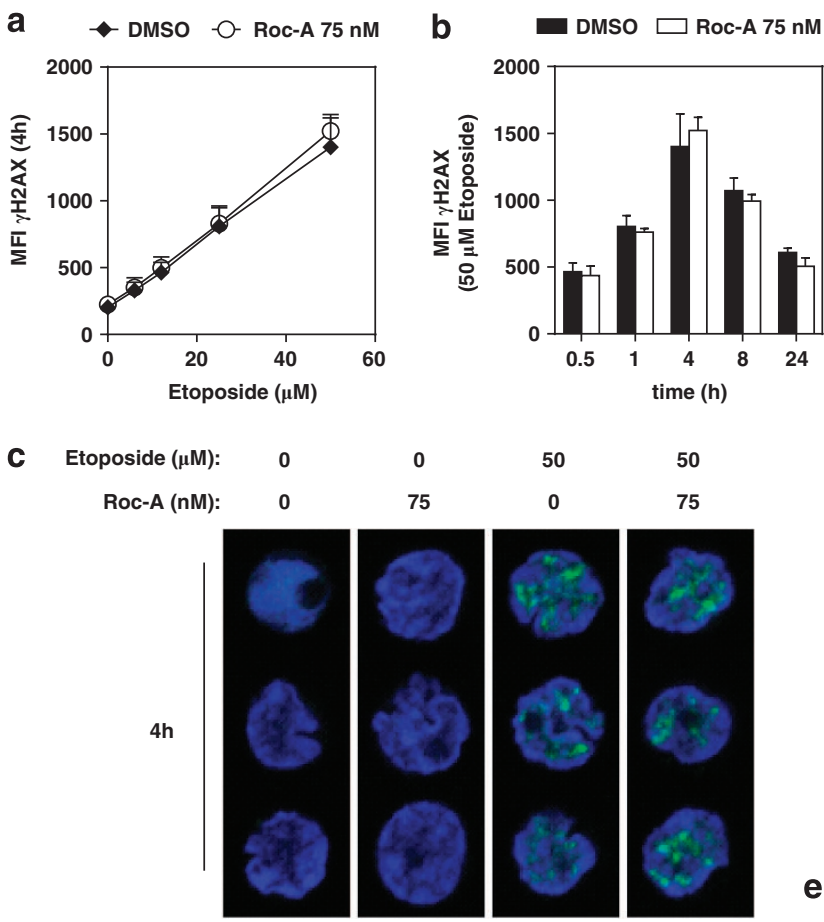

e
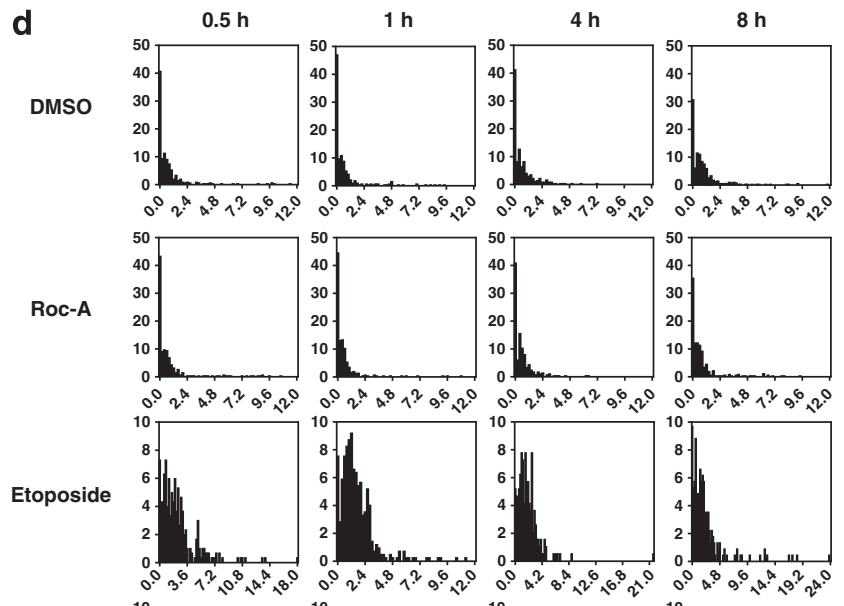

$0^{0} v^{*} x^{8} \lambda^{2} 9^{6} \wedge^{0}$

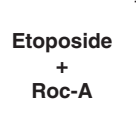

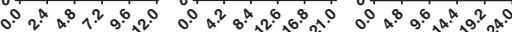
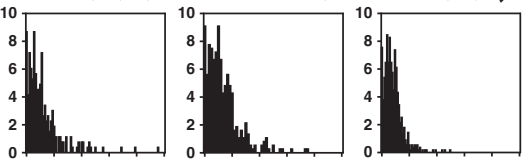

응

e $\square$ DMSO $\square$ Roc-A $\square$ Etoposide $\square$ Etoposide + Roc-A

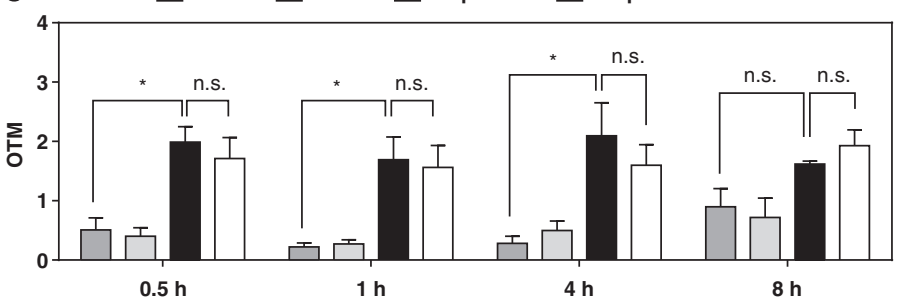

Figure 2 Roc-A does not protect T cells from genotoxin-induced DNA damage. (a) Roc-A does not prevent Etoposide-induced increase in $\gamma$-H2AX. T cells were treated with solvent (DMSO) or different concentrations of Etoposide in the presence of Roc-A ( $75 \mathrm{nM}$ ) or solvent (DMSO) for $4 \mathrm{~h}$. DSB induction was assessed by determination of the mean fluorescence intensity (MFI) of $\gamma$-H2AX-stained cells. Data are an average of three independent experiments. Error bars (S.D.) are shown. (b) Kinetic analysis of the effect of Roc-A on Etoposide-induced DSBs. T cells were treated with $50 \mu \mathrm{M}$ Etoposide in the presence of Roc-A (75 nM) or solvent (DMSO) for different times and DSB induction was determined as described in (a). Data are an average of three independent experiments. Error bars (S.D.) are shown. (c) Confocal microscopy analysis of Etoposide-induced $\gamma$-H2AX-foci in the absence or presence of Roc-A. Nuclei of cells, obtained from (a) and (b), were stained with DAPI (blue) and imaged by confocal microscopy. $\gamma-\mathrm{H} 2 \mathrm{AX}$ staining is shown in green. Three representative nuclei are shown for each treatment. (d) Comet assay to monitor the effect of Roc-A on Etoposideinduced DNA damage in T cells. Peripheral blood T cells were treated with solvent (DMSO) or Etoposide $(50 \mu \mathrm{M})$ in the presence of Roc-A (75 nM) or solvent (DMSO) for different time periods as indicated. A comet assay was carried out subsequently. The distribution of olive tail moments (OTM) among treated cells is shown. Data are representative of three different healthy donors. (e) Summary of the data obtained from (d). Results are an average of the mean OTM of three different healthy donors. Error bars (S.D.) are shown. ${ }^{*} P<0.05$, calculated by the unpaired Student's $t$-test with Welch's correction

cells from Etoposide-induced apoptosis (Figure 4c, lower panel). As siRNA-mediated knockdown of p53 could not fully block p53 expression, we examined the effect of Roc-A on p53 knockout (KO) cells. Splenocytes derived from wildtype (WT) and p53-KO mice were treated with Etoposide in the presence or absence of Roc-A. In line with the data observed in primary human cells, Roc-A protected splenocytes derived from p53-WT but not from p53-KO animals against Etoposide-induced cell death (Figure 4d). These results demonstrate that p53 plays an essential role in Roc-Amediated chemoprotection.

Roc-A does not protect malignant cells with nonfunctional p53. As Roc-A-mediated protection of nonmalignant cells from DNA damage-induced cell death is largely p53 dependent, we predicted that Roc-A may protect cancer cells having functional p53 but would not protect cancer cells having nonfunctional p53. As expected, Roc-A neither protected p53-mutated (L1236, ${ }^{26}$ Hut-78, ${ }^{27}$ DND-41 ${ }^{28}$ and SCLC-21 ${ }^{29}$ ) nor p53-deficient ( $\mathrm{HL}-60^{29}$ ) cancer cell lines against Etoposide-induced cell death (Figure $5 \mathrm{a}$ ). We then further tested cancer cell lines EU-3, ${ }^{30}$ IM- $9,{ }^{31}$ Reh, ${ }^{30}$ SKW6. $4^{32}$ and $\mathrm{NCl}-\mathrm{H} 209^{33}$ that have a WT p53 protein. The experiments showed that EU-3, SKW6.4 and IM-9 cells were protected by Roc-A from Etoposide-induced cell death but to a lesser extent than nonmalignant cells (Figure $5 \mathrm{~b}$ and Supplementary Figure S3). Thus, Roc-A may also protect some p53-WT tumors from DNA-damaging drugs.

Roc-A suppresses p53 upregulation via inhibition of protein synthesis. The protein expression of p53 can be regulated at the level of transcription, translation and ubiquitination-mediated degradation. ${ }^{34}$ It has been shown that upon DNA damage p53 undergoes post-translational 
a

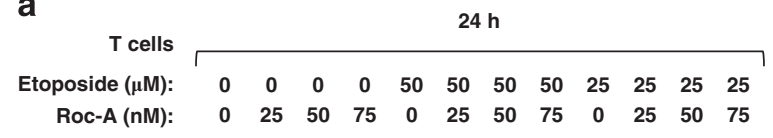

b

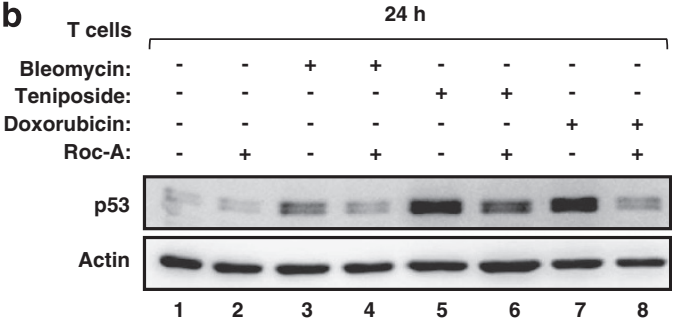

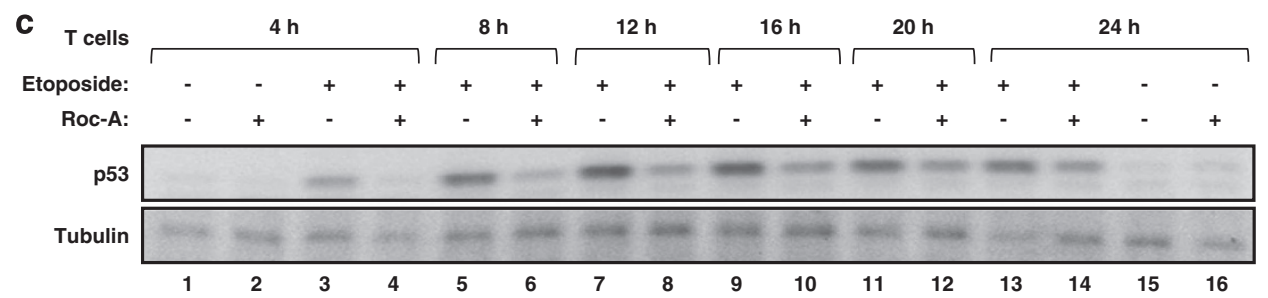
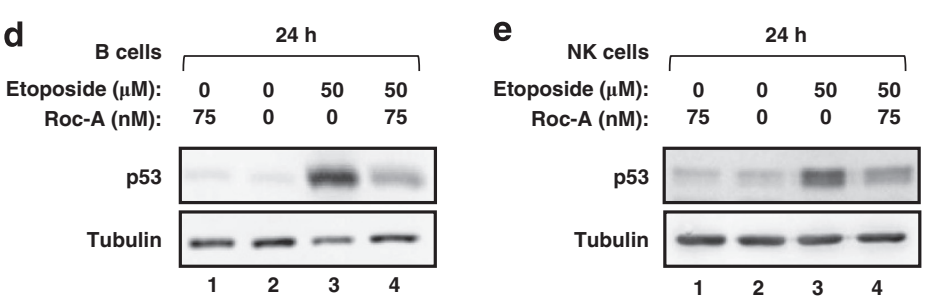

Figure 3 Roc-A blocks genotoxin-induced upregulation of p53. (a and b) Roc-A inhibits Etoposide- (a), Bleomycin-, Teniposide- and Doxorubicin (b)-induced p53 upregulation in T cells. T cells were treated with solvent or different anticancer drugs in the presence of different concentrations of Roc-A or solvent (DMSO) as indicated. Cell lysates were subjected to immunoblot analysis with antibodies against p53. Actin or tubulin were used as loading controls. Data are representative of three independent experiments. (c) Kinetic analysis of the effect of Roc-A on Etoposide-induced p53 upregulation. T cells were treated with solvent (DMSO) or $50 \mu \mathrm{M}$ Etoposide in the presence of $75 \mathrm{nM}$ Roc-A or solvent (DMSO) for different time periods as indicated. Cell lysates were subjected to immunoblot analysis with antibodies against p53 and tubulin. Data are representative of two independent experiments. ( $\mathbf{d}$ and $\mathbf{e})$ Roc-A inhibits Etoposide-induced p53 upregulation in B cells (d) and NK cells (e). Cells were treated with solvent (DMSO) or Etoposide in the presence of Roc-A or solvent (DMSO) as indicated and cell lysates were subjected to immunoblot analysis. Data are representative of two independent experiments. In (a, b, d), the double band observed for p53 is likely to occur because of a heterozygous p53 R72P polymorphism

modifications leading to its deubiquitination and, thus, stabilization. ${ }^{35}$ To investigate whether Roc-A could decrease p53 stability, we treated T cells with the proteasome inhibitor Bortezomib to block proteasome-mediated degradation. Bortezomib treatment led to an increase in p53 in the absence of Roc-A (Figure 6a). However, Bortezomib could not increase p53 in the presence of Roc-A and also did not interfere with the ability of Roc-A to block Etoposide-induced p53 upregulation (Figure 6a). To further investigate the effect of Roc-A on p53 stability, the status of p53 ubiquitination was analyzed after Etoposide treatment in the absence or presence of Roc-A. Etoposide treatment led to a decrease in p53 ubiquitination. However, Roc-A had no effect on p53 ubiquitination (Figure $6 b$ ). These results demonstrate that Roc-A is unlikely to suppress p53 upregulation through decreasing p53 stability.

In addition, p53 has been shown to be upregulated at the translational level following DNA damage. ${ }^{36,37}$ Roc-A has been well documented to inhibit protein translation. ${ }^{18,19,38,39}$ Thus, we hypothesized that Roc-A-mediated suppression of genotoxin-induced p53 upregulation may be caused by inhibition of $\mathrm{p} 53$ protein synthesis. To test this, we examined the effects of different Roc-A derivatives that have been shown to exert different activities on inhibition of ERKmediated protein synthesis. ${ }^{18}$ By means of $\left[{ }^{35} \mathrm{~S}\right]$ methionine incorporation analysis, Roc-A, $-A B,-J,-A R$ and $-Q$, which have been shown to inhibit ERK activation with different efficacies, ${ }^{18}$ inhibited $\left[{ }^{35}\right.$ S]methionine incorporation at different degrees that correlated with different levels of protection of normal T cells from Etoposide-induced cell death (Figure 6c). In contrast, Roc-AA, -AF and -I, which do not show any or very little inhibitory effect on ERK activity, ${ }^{18}$ did not inhibit protein translation and did not protect $\mathrm{T}$ cells against Etoposideinduced cytotoxicity (Figure 6c)

To confirm that Roc-A inhibits p53 protein synthesis, we carried out a $\left[{ }^{35}\right.$ S $]$ methionine-metabolic pulse-labeling experiment and then immunoprecipitated p53 after Etoposide treatment. The experiment showed that Roc-A suppressed $\left[{ }^{35}\right.$ S $]$ methionine incorporation into the p53 protein (Figure $6 \mathrm{~d}$ ). To further exclude that Roc-A influences p53 expression at the transcriptional level, we examined p53 mRNA expression levels upon Etoposide treatment in the presence of Roc-A or solvent (DMSO) by quantitative real-time PCR. The experiment showed that Roc-A does not reduce p53 mRNA expression in Etoposide-treated cells (Figure 6e). Thus, Roc-A suppresses DNA damage-induced upregulation of p53 at the translational level.

\section{Discussion}

Chemotherapy is broadly used among current standard treatment modalities for cancer patients, in particular for patients suffering from metastases. Most currently used 

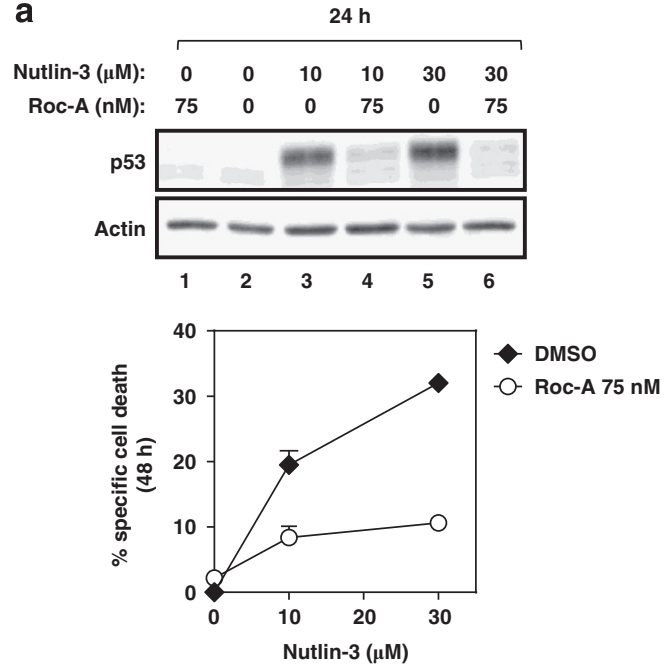

C
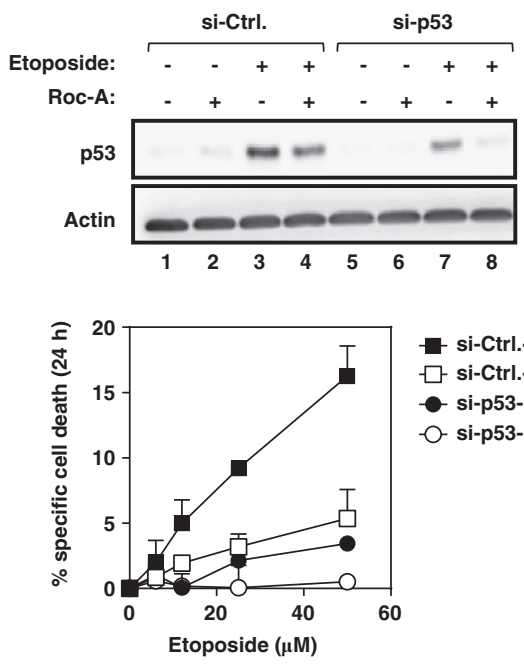

- si-Ctrl.-DMSO $\square$ si-Ctrl.-Roc-A - si-p53-DMSO - si-p53-Roc-A
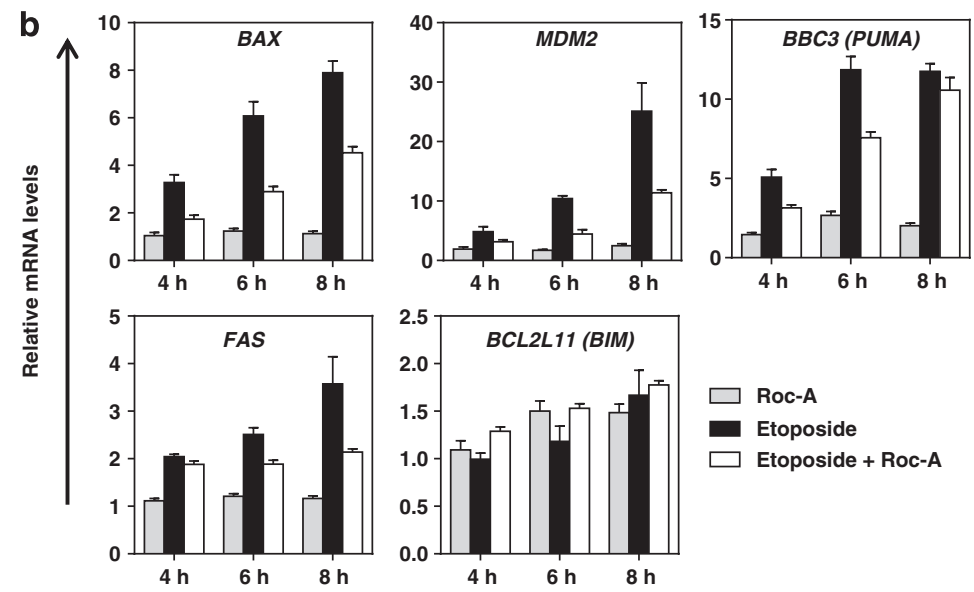

d

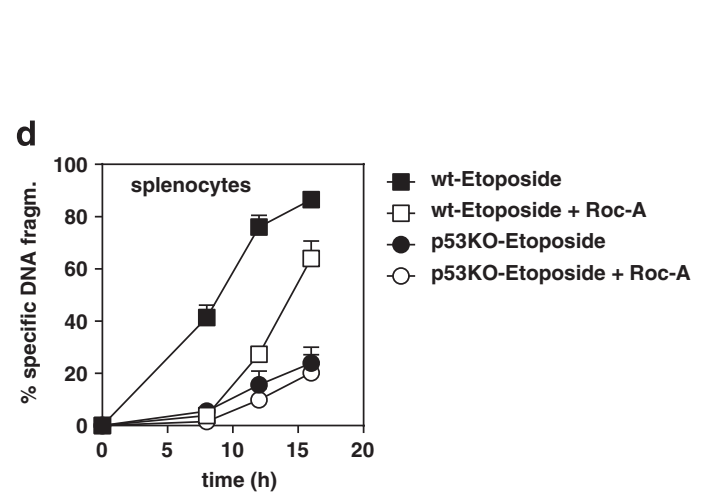

$\square$ Roc-A

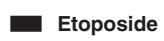

$\square$ Etoposide + Roc-A

Figure 4 Roc-A-mediated chemoprotection depends on p53. (a) Roc-A inhibits Nutlin-3-induced p53 upregulation and protects T cells from Nutlin-3-induced cell death. T cells were treated with solvent (DMSO) or Nutlin-3 in the presence of Roc-A or solvent (DMSO) as indicated. After $24 \mathrm{~h}$ of treatment, the expression levels of p53 were analyzed by immunoblot (upper panel). Cell death was determined after $48 \mathrm{~h}$ of treatment by FSC/SSC profile (lower panel). Data are representative of three independent experiments. Error bars (S.D.) are shown. (b) Roc-A reduces Etoposide-induced mRNA expression of p53 target genes. T cells were treated with solvent (DMSO) or Etoposide (50 $\mu \mathrm{M})$ in the presence of Roc-A $(75 \mathrm{nM})$ or solvent (DMSO) for different time periods as indicated. Total RNA was isolated and subjected to quantitative real-time PCR for $B A X, M D M 2, B B C 3$ (PUMA), FAS and BCL2L11 (BIM). Data are presented as fold change in mRNA levels and normalized to control treatment with solvent (DMSO). Data are representative of three independent experiments. Error bars (minimum and maximum) are shown. (c) siRNA-mediated knockdown of p53 mimics the protective effect of Roc-A. T cells were transfected with scrambled (si-Ctrl.) or specific siRNA targeting p53 (si-p53). At $24 \mathrm{~h}$ after transfection, T cells were treated with solvent (DMSO) or Etoposide (50 $\mu \mathrm{M}$ ) in the presence of Roc-A $(75 \mathrm{nM})$ or solvent (DMSO) as indicated for $24 \mathrm{~h}$. The expression levels of p53 were analyzed by immunoblot and cell death was determined by FSC/SSC profile. Data are representative of three independent experiments. Error bars (S.D.) are shown. (d) Roc-A-mediated protection is abolished in p53 ${ }^{-1-}$ splenocytes. Splenocytes from p53 ${ }^{-1-}$ or

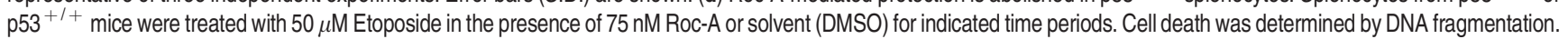
Data are an average of four independent experiments. Error bars (S.D.) are shown

anticancer drugs are genotoxins that induce DNA damage. This therapy has a major drawback of causing severe side effects. Because of these side effects, dosages have to be reduced or the treatment has to be discontinued completely. In this study we show that the TCM compound Roc-A can reduce DNA-damaging drug-induced cytotoxicity in human and murine primary cells. The protective effect of Roc-A is not limited to a certain cell type or a specific DNA-damaging agent (Figure 1). Thus, our data strongly suggest a potential use of Roc-A as a chemoprotective agent.

Investigation of the molecular mechanisms by which Roc-A protects normal cells from chemotherapy-induced cytotoxicity revealed that p53 is a key factor in Roc-A-mediated protection. We show that Roc-A does not reduce genotoxininduced DNA damage (Figure 2), but inhibits genotoxininduced upregulation of p53 in different primary cells (Figure 3). The essential role of p53 in Roc-A-mediated protection is evidenced by the following: (1) upregulation of p53 by Nutlin-3 (without inducing DNA damage) could be suppressed by Roc-A and downregulation of p53 coincided with reduced cell death in Nutlin-3-treated normal $T$ cells (Figure 4a); (2) suppression of p53 expression by Roc-A coincided with downregulation of Etoposide-induced p53target genes, such as BAX, MDM2, BBC3 (PUMA) and FAS in normal T cells (Figure 4b); (3) siRNA-mediated knockdown of p53 decreased p53 protein levels to a similar extent as 

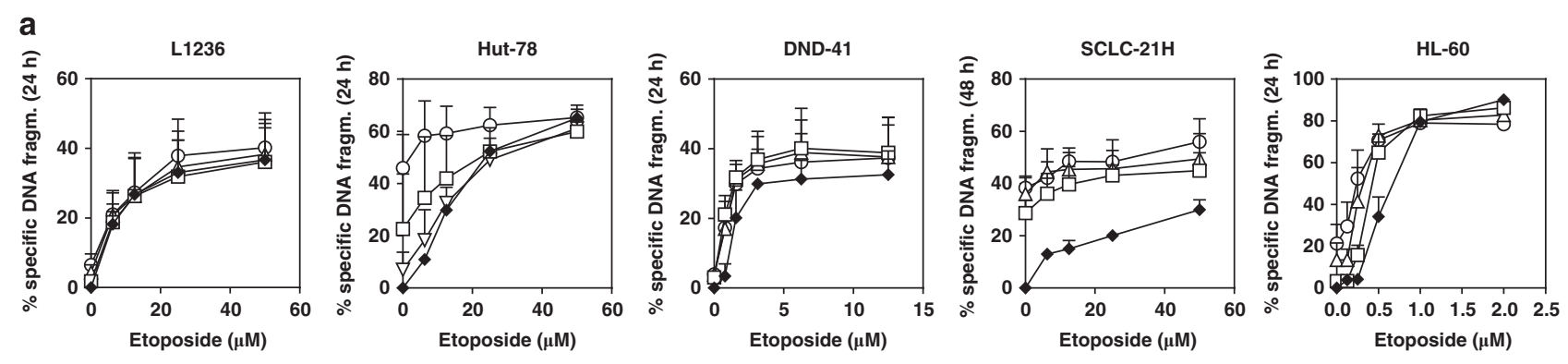

$\uparrow$ DMSO

$\neg$ Roc-A $12.5 \mathrm{nM}$

$\square$ Roc-A $25 \mathrm{nM}$

$\triangle$ Roc-A $50 \mathrm{nM}$

- Roc-A $75 \mathrm{nM}$
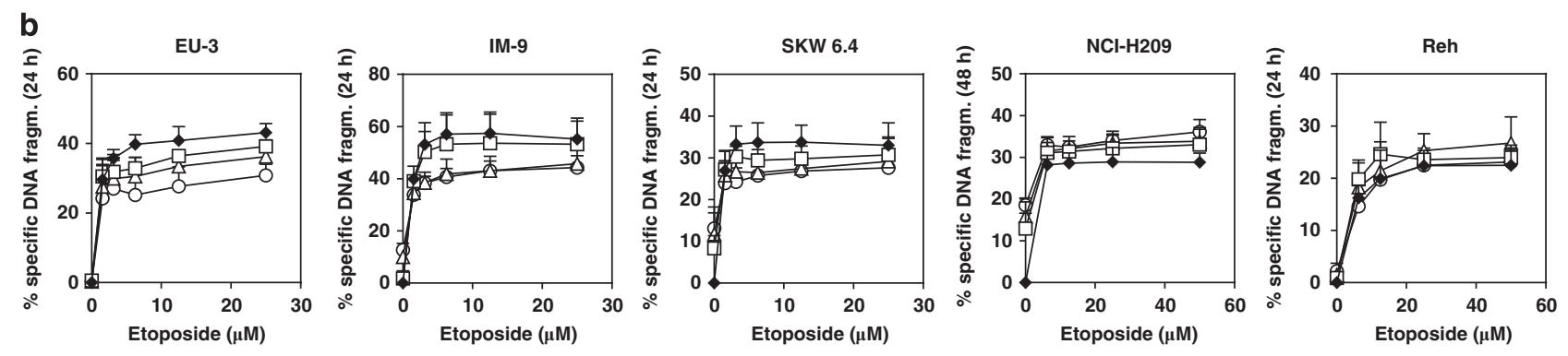

DMSO $\quad \nabla-$ Roc-A $12.5 \mathrm{nM}$

$\triangle$ Roc-A 50 nM

Roc-A $75 \mathrm{nM}$

Figure 5 Roc-A does not protect cancer cell lines with nonfunctional p53. p53-mutated or -deficient cancer cell lines (a) and p53 WT cell lines (b) were treated with solvent (DMSO) or different concentrations of Etoposide in the presence of increasing amounts of Roc-A or solvent (DMSO) as indicated. Cell death was determined by DNA fragmentation after 24 or $48 \mathrm{~h}$ of treatment as indicated. Results are averages of three independent experiments. Error bars (S.D.) are shown

Roc-A treatment and resulted in a similar level of protection of T cells from Etoposide-induced cell death (Figure 4c); and (4) p53-WT but not p53-KO splenocytes were protected by Roc-A from Etoposide-induced cell death (Figure 4d). These data are consistent with the fact that p53 is involved in DNA damage-induced apoptosis ${ }^{23,40}$ and that decreased p53 protein levels confer resistance to a large number of DNAdamaging chemotherapeutics in vitro ${ }^{23,40}$ and in vivo. ${ }^{41}$

Approximately $50 \%$ of all known cancers are either deficient for p53 or carry a mutation in p53 that abolishes p53-WT function. ${ }^{42}$ We show that Roc-A does not protect Etoposidetreated tumor cell lines that either contain p53 mutations $\left(\mathrm{L} 1236,{ }^{26} \mathrm{Hut}-78,{ }^{27} \mathrm{DND}-41^{28}\right.$ and SCLC-21H ${ }^{29}$ ) or that are p53-deficient $\left(\mathrm{HL}-60^{29}\right)$ (Figure $\left.5 \mathrm{a}\right)$. These results indicate that Roc-A may be used to reduce the side effects of chemotherapy in the treatment of p53-deficient or -mutated cancers. As p53 plays a decisive role in Roc-A-mediated protection, one can presume that Roc-A may protect p53-WT tumors against genotoxin-induced cell death. As predicted, Roc-A was shown to indeed reduce Etoposide-induced cell death in several p53WT tumor cell lines including EU-3 acute lymphoblastic leukemia cells, SKW6.4 leukemic B cells and IM-9 chronic myeloid leukemia cells (Figure $5 b$ ). However, the protective effect of Roc-A on p53-WT tumor cells was less efficient compared with nonmalignant cells (Figure 1 and Supplementary Figure S3). Intriguingly, some p53-WT tumor cells, for example, the acute lymphoblastic leukemia cell line Reh and the small cell lung cancer cell line $\mathrm{NCl}-\mathrm{H} 209$, were not protected by Roc-A (Figure $5 b$ ). This result may be explained by mutations of genes in the p53 signaling pathway that often occur in p53-WT cancers. ${ }^{42,43}$ In addition, Roc-A has been shown to have a much higher cytotoxicity on cancer than on nonmalignant cells by differential regulation of activities of mitogen-activated protein kinases. ${ }^{44}$ Furthermore, Roc-A has been shown to inhibit the Ras/CRaf/MEK/ERK signaling pathway that is one of the key signaling pathways regulating tumor survival. ${ }^{18,45}$

In this study, we also investigated the molecular mechanism by which Roc-A inhibits DNA damage-induced p53 upregulation. Under unstressed conditions, p53 is negatively regulated by Mdm2 that binds to and inhibits p53 activity and leads to its degradation by the ubiquitination-mediated proteasomal pathway. ${ }^{46}$ Genotoxic stress has been shown to inhibit Mdm2-mediated p53 degradation and increase the stability and, consequently, protein levels of p53. ${ }^{35}$ Our experiments showed that Roc-A neither alters the basal level of p53 ubiquitination nor the level of p53 ubiquitination upon Etoposide treatment (Figure 6b). Moreover, blocking proteasomal activity did not lead to a reduction in Roc-A-mediated suppression of p53 upregulation (Figure 6a). Thus, we conclude that Roc-A does not affect p53 stability. Genotoxic stress can also increase the expression of p53 at the translational level. ${ }^{36,37}$ Roc-A and its derivatives are potent inhibitors of protein synthesis. ${ }^{14,15,18,19,38}$ Indeed, Roc-A and its active derivatives Roc-AB, J, AR and $Q,{ }^{18}$ but not the inactive derivatives Roc-AA, AF and I, ${ }^{18}$ were shown to inhibit Etoposide-induced protein translation (Figure $6 \mathrm{c}$ ). The degree of translation inhibition correlated with the efficacy of chemoprotection by Roc-A and its derivatives (Figure 6c). Moreover, Roc-A was shown to inhibit p53 translation (Figure 6d). Furthermore, Roc-A did not reduce the mRNA levels of p53 (Figure 6e). These data demonstrate that Roc-A inhibits DNA damage-induced upregulation of p53 by inhibition of protein synthesis. 

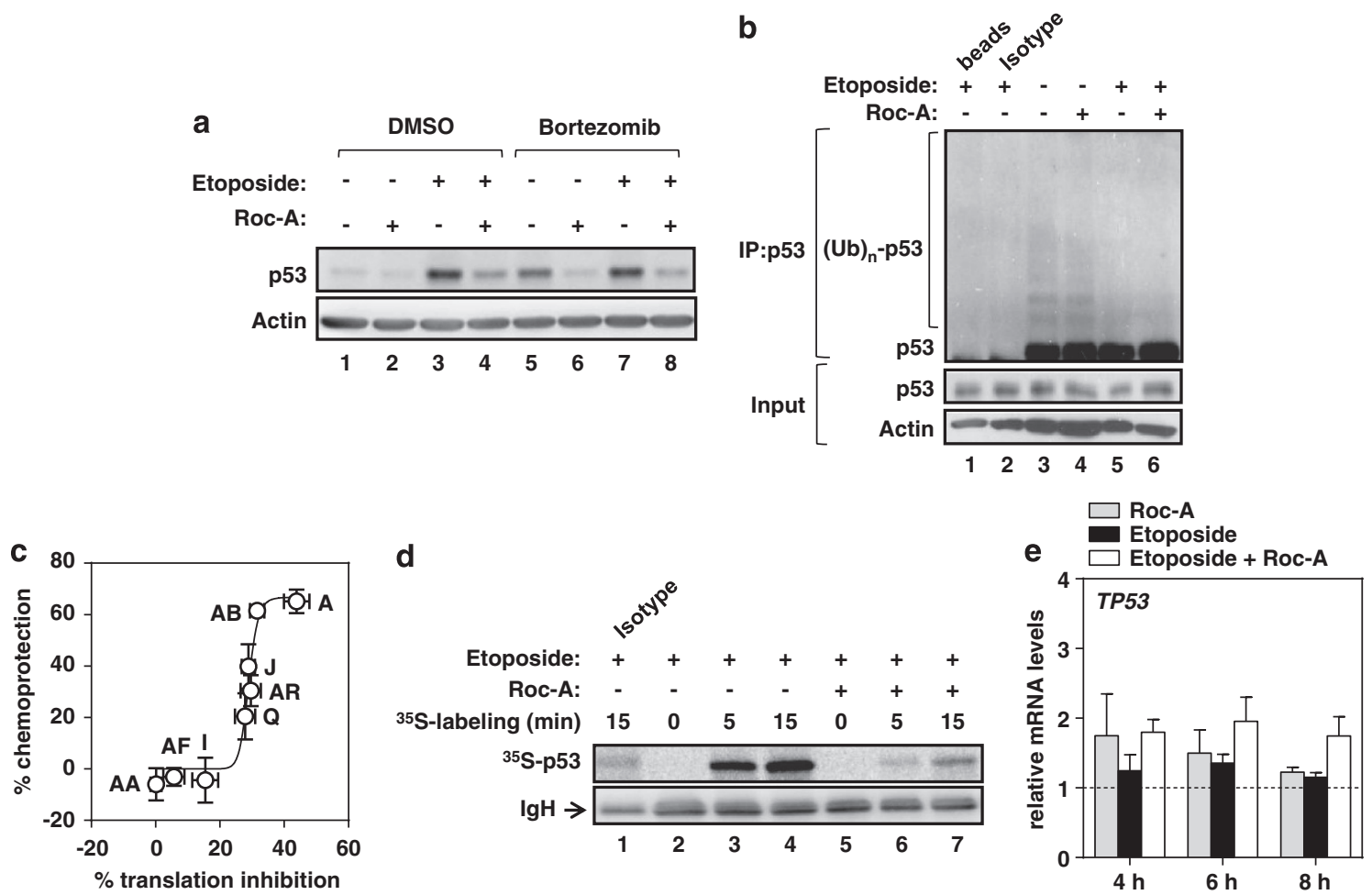

Figure 6 Roc-A inhibits upregulation of p53 via inhibition of protein synthesis. (a) Inhibition of proteasome-mediated degradation does not influence Roc-A-mediated chemoprotection. T cells were treated with solvent (DMSO) or $100 \mathrm{nM}$ Bortezomib to block proteasome-mediated protein degradation and treated with solvent (DMSO) or $50 \mu \mathrm{M}$ Etoposide in the presence of $75 \mathrm{nM}$ Roc-A or solvent (DMSO) for $4 \mathrm{~h}$. Cell lysates were subjected to immunoblot analysis with antibodies against p53 and Actin. Data are representative of three independent experiments. (b) Roc-A does not influence ubiquitination of p53. T cells were treated with Bortezomib, Etoposide and Roc-A as in (a). After $4 \mathrm{~h}$ of treatment, cell lysates were used for immunoprecipitation against p53. Isotype-matched antibody-coupled beads and uncoupled beads were used as controls. Ubiquitinated p53 ((UB) $n$-p53) is indicated. Data are representative of two independent experiments. (c) Inhibition of protein translation by Roc-A or its derivatives correlates with their chemoprotective effects. Effects of Roc-A and its derivatives (-AB, -J, -AR, -Q, -I, -AF and -AA) on protein synthesis in T cells was determined by measuring the amounts of incorporation of $\left[{ }^{35} \mathrm{~S}\right.$-labeled methionine. Cell death was determined by DNA fragmentation of T cells treated with solvent (DMSO) or $50 \mu \mathrm{M}$ Etoposide in the presence of $75 \mathrm{nM}$ of different Roc-derivatives or solvent (DMSO) for $24 \mathrm{~h}$. The percentage of chemoprotection was determined by calculating the percentage of protection against Etoposide-induced cell death. The data are shown by plotting the percentage of translation inhibition against the percentage of chemoprotection. Data are an average of three independent experiments. Error bars (S.E.M.) are shown. An allosteric sigmoidal regression curve was plotted against the experimental data. $R^{2}=0.96$. (d) Roc-A inhibits p53 protein translation. T cells were treated according to (a), followed by metabolic pulse-labeling for indicated time periods and immunoprecipitation. Data are representative of three independent experiments. (e) Roc-A does not reduce the mRNA levels of p53. T cells were treated with solvent (DMSO) or $50 \mu \mathrm{M}$ Etoposide in the presence of $75 \mathrm{nM}$ Roc-A or solvent (DMSO) for indicated time periods. Total RNA was isolated and was subjected to quantitative real-time PCR for TP53. Data are presented as fold increase in mRNA levels determined by comparison of HPRT1 gene expression levels with TP53 and normalized to control treatment with solvent (DMSO). Data are an average of three independent experiments. Error bars (S.D.) are shown

p53 is a well-known tumor suppressor. Thus, blocking p53 expression might increase the risk of tumor development. However, a number of studies show that transient pharmacological or genetic inactivation of p53 before or after genotoxic stress does not lead to increased carcinogenesis. ${ }^{47-49}$ Moreover, recent publications indicate that the tumor-suppressor function of p53 is independent from its functions on apoptosis and cell cycle. ${ }^{50,51}$

In this study, we also show that, in principle, all bioactive derivatives of Roc-A may protect normal cells from genotoxininduced cytotoxicity (Figure 6c). In line with our studies, several compounds belonging to the same structural family of Roc-A were recently shown to protect rat and murine cardiomyocytes against doxorubicin-induced apoptosis. ${ }^{52,53}$ Doxorubicin is also a DNA-damaging anticancer drug. Therefore, cardioprotection by these compounds may also involve p53. Moreover, p53 has been implicated in certain neurological disorders, such as Alzheimer's and Parkinson's disease. ${ }^{54,55}$
Interestingly, some structural-related compounds of Roc-A were shown to have neuroprotective effects in vitro on neuron cells and in vivo in animal models of Parkinson's disease and stroke. ${ }^{53,56}$ In this regard, our results may offer a potential mechanism for the neuroprotective action of these compounds.

Taken together, our data demonstrate that Roc-A selectively protects nonmalignant human primary cells against DNA damage-induced apoptosis via a p53-dependent mechanism. Thus, Roc-A and its derivatives may be attractive compounds for the treatment of side effects of current chemotherapy.

\section{Materials and Methods}

Reagents and Roc derivatives. Etoposide (Biotrend Chemikalien GmbH, Cologne, Germany), Bleomycin (sulfate) (Cayman Chemical Company, Ann Arbor, MI, USA), Doxorubicin (Sigma-Aldrich, Munich, Germany), Nutlin-3 (Sigma-Aldrich) and Teniposide (Enzo Life Sciences, Lörrach, Germany) were used for apoptosis 
induction. Roc-A (>98\% pure; Enzo Life Sciences) and derivatives Roc-AA (C-1-O-acetyl-methylrocaglate), Roc-AB (1-O-acetyl-rocaglamide), Roc-AF (30,40-methylendioxy-methylro-caglate), Roc-AR (1-oxo-40-demethoxy-30,40-methylenedioxyrocaglaol), Roc-I (C-1-O-acetyl-30-hydroxy-rocaglamide), Roc-J (30-hydroxyaglafoline) and Roc-Q (demethylrocaglamide) were isolated from Aglaia species to the purity of $>98 \%$ as determined by high-performance liquid chromatography (HPLC).

Primary human cells and cell cultures. The human malignant cell lines EU-3 (acute lymphoblastic leukemia), DND-41 (T-cell leukemia), Hut-78 (T-cell lymphoma), SKW6.4 (B-cell leukemia), Reh (acute lymphoblastic leukemia), IM-9 (chronic myeloid leukemia), HL-60 (promyelocytic leukemia), L1236 (Hodgkin's lymphoma) and $\mathrm{NCl}-\mathrm{H} 209$ (small cell lung cancer) were cultured at $37^{\circ} \mathrm{C}$ with $5 \%$ $\mathrm{CO}_{2}$ in RPMI-1640 medium (Sigma-Aldrich) supplemented with 10\% FCS, $100 \mathrm{U} / \mathrm{ml}$ Penicillin (Sigma-Aldrich) and $100 \mu \mathrm{g} / \mathrm{ml}$ Streptamycin (Sigma-Aldrich). SCLC-21H cells (small cell lung cancer) were cultured in DMEM medium (Sigma-Aldrich) supplemented with $10 \%$ FCS. Peripheral blood T lymphocytes were isolated as previously described. ${ }^{57} \mathrm{~B}$ lymphocytes and NK cells were isolated by magneticactivated cell sorting using 'B cell isolation kit II' (Miltenyi Biotech, Bergisch Gladbach, Germany) and 'NK cell isolation kit, human' (Miltenyi Biotech), respectively, according to the manufacturer's instructions. Human neutrophils were separated from peripheral blood mononuclear cells by Ficoll-Paque density centrifugation, followed by incubation in $1.05 \%$ dextran for $30 \mathrm{~min}$ at room temperature. Remaining erythrocytes were lysed by resuspension in ice-cold $0.2 \%$ sodium chloride solution. After $1 \mathrm{~min}$, ice-cold $1.6 \%$ sodium-chloride solution was added and lysis was stopped by addition of PBS and neutrophils were resuspended in medium at a concentration of $2 \times 10^{6} \mathrm{celll} / \mathrm{ml}$. Human primary cardiomyocytes were purchased from PromoCell (Heidelberg, Germany) and cultured in myocyte growth medium (PromoCell). Remaining primary human cells were cultured in RPMI-1640 medium with the same conditions described above.

Cell viability screen. Human peripheral blood T lymphocytes were treated for $24 \mathrm{~h}$ with the following compounds: Atropine (VWR International, Darmstadt, Germany), Artemisinin (MP Biomedicals, Eschwege, Germany), Embelin (SigmaAldrich), Rocaglamide, Camphor (MP Biomedicals), Caffeine (Sigma-Aldrich), Luteolin (Sigma-Aldrich), Curcumin (Alexis Biochemicals, San Diego, CA, USA), Wogonin (Wako Pure Chemical Industries, Osaka, Japan), $\beta$-Escin (MP Biomedicals), Berberine (Biomol, Hamburg, Germany), Triptolide (Enzo Life Sciences), Chrysin (Sigma-Aldrich), Baicalein (Biomol), Resveratrol (MP Biomedicals), Quercetin (Sigma-Aldrich), Emodin (Biotrend Chemikalien GmbH), Baicalin (Sigma-Aldrich) and Coumarin (Fisher Scientific, Schwerte, Germany). Cell viability was determined by the Cell-Titer Glo assay (Promega) according to the manufacturer's instructions.

Apoptosis measurements. Apoptotic cell death was determined by AnnexinV staining, cellular forward scatter/side scatter (FSC/SSC) profile or DNA fragmentation. For AnnexinV staining, $2 \times 10^{5}$ cells were treated with different drugs for indicated time periods, washed with AnnexinV binding buffer $(0.01 \mathrm{M}$ Hepes, $0.14 \mathrm{M} \mathrm{NaCl}, 2.5 \mathrm{mM} \mathrm{CaCl}$ ), and stained with AnnexinV-FITC antibody (Immunotools, Friesoythe, Germany) and 7-amino-actinomycin D (SigmaAldrich) for $30 \mathrm{~min}$ at $4^{\circ} \mathrm{C}$. The amount of AnnexinV-positive cells was determined by FACS measurement. DNA fragmentation was determined according to the method of Nicoletti et al. ${ }^{58}$ Briefly, $2 \times 10^{5}$ cells were treated as indicated, washed with PBS and lysed in Nicoletti buffer $(0.1 \%$ sodium citrate, $0.1 \%$ Triton X-100, $50 \mu \mathrm{g} / \mathrm{ml}$ propidium iodide). DNA fragmentation was determined by FACS Apoptotic-like cells were determined by FSC/SSC index. Specific DNA fragmentation/specific AnnexinV-positive cells/specific cell death was calculated as follows: (percentage of experimental DNA fragmentation (or AnnexinV-positive cells or cell death)-percentage of spontaneous DNA fragmentation (or AnnexinV-positive cells or cell death)/(100 - percentage of spontaneous DNA fragmentation (or AnnexinV-positive cells or cell death)) $\times 100$.

Immunoblot analysis. Immunoblot analysis was carried out as previously described. ${ }^{18}$ Briefly, $4-20 \times 10^{6}$ cells were treated with different reagents as indicated and lysed in RIPA buffer $(50 \mathrm{mM}$ Tris $\mathrm{HCl}, 137 \mathrm{mM} \mathrm{NaCl}, 0.5 \% \mathrm{Na}$ Deoxycholate, $1 \%$ Triton X-100, $0.1 \%$ SDS, protease inhibitors). Proteins were separated by SDS-PAGE and transferred to a nitrocellulose membrane (Amersham Biosciences, Little Chalfon, UK) using a semi-dry blotting approach. The following antibodies were used: p53 (DO-1) antibody was purchased from Santa Cruz Biotechnology (Heidelberg, Germany). Tubulin and actin (A5441) antibodies were purchased from Sigma-Aldrich (St. Louis, MO, USA).
Immunoprecipitation and metabolic pulse-labeling experiments. For immunoprecipitation, cells were treated for $4 \mathrm{~h}$ with Etoposide and/or Roc-A in the absence or presence of $100 \mathrm{nM}$ Bortezomib (Enzo Life Sciences). In the case of metabolic pulse-labeling experiments, treatment was followed by adding $100 \mu \mathrm{Ci} / \mathrm{ml}$ of $\left.{ }^{35} \mathrm{~S}\right]-$ methionine-labeling mix (PerkinElmer, Waltham, MA, USA) to the medium for 0-15 min. Subsequently, cells were washed in ice-cold PBS, lysed in IP buffer $(20 \mathrm{mM}$ Tris- $\mathrm{HCl}, 5 \mathrm{M} \mathrm{NaCl}, 2 \mathrm{mM}$ EDTA, $1 \%$ Triton $\mathrm{X}-100$, protease inhibitors) and centrifuged $(10000 \times g, 20 \mathrm{~min})$ to clear lysates. Aliquots were taken for input control and lysates were incubated overnight with sepharosecoupled protein A beads, anti-p53 antibody (FL-393; Santa Cruz) or isotype control antibody (Sigma-Aldrich). Two wash steps with IP buffer preceded boiling of beads in denaturing sample buffer at $95^{\circ} \mathrm{C}$ for $5 \mathrm{~min}$. Incorporation of $\left[{ }^{35} \mathrm{~S}\right]$-methionine into p53 protein was detected by the phosphoimaging system FLA-7000 IR (Fujfilm Europe GmbH, Düsseldorf, Germany).

Translation assay. The relative amount of protein synthesis was determined by measuring the amount of incorporation of $\left[{ }^{35} \mathrm{~S}\right]-$ methionine into the protein. Briefly, cells were precultured in methionine-free medium (supplemented with $10 \%$ dialyzed FCS) for $3 \mathrm{~h}$, followed by incubation with $3.5 \mu \mathrm{Ci}$ of $\left[{ }^{35} \mathrm{~S}\right]$-methioninelabeling mix (PerkinElmer) per $8 \times 10^{5}$ cells for $6 \mathrm{~h}$ as indicated. After the treatment, cells were washed twice with ice-cold PBS and lysed in RIPA buffer. Then, $50 \mu \mathrm{l}$ of each lysate was added to $1 \mathrm{ml}$ of Liquid Scintillation Cocktail solution (Beckman Coulter, Brea, CA, USA) and the amount of incorporated radioactivity was determined by liquid scintillation counting

Isolation of primary murine splenocytes. $\mathrm{P} 53^{-1-} \mathrm{C} 57 \mathrm{BI} / 6$ mice (B6.Trp53tm1Tyj) were kindly provided by Liu H-K (German Cancer Research Center, Heidelberg, Germany). Spleens of 8-12-week-old p53 $3^{-1-}$ and $p 53^{+1+}$ mice were isolated in parallel, minced and incubated for $30 \mathrm{~min}$ in RPMI-1640 medium supplemented with DNase I $(50 \mathrm{U} / \mathrm{ml})$ and Collagenase IV $(1 \mathrm{mg} / \mathrm{ml})$ at $37^{\circ} \mathrm{C}$ and $5 \% \mathrm{CO}_{2}$. Splenocytes were filtered by $40 \mu \mathrm{M}$ cell strainer, washed twice with ice-cold wash buffer (PBS, 0.5\% FCS, $2 \mathrm{mM}$ EDTA) and resuspended in Oxford medium (RPMl-1640, 10\% FCS, $100 \mu \mathrm{g} / \mathrm{ml}$ penicillin, $100 \mu \mathrm{g} / \mathrm{ml}$ streptamycin, $10 \mathrm{mM}$ Hepes, $50 \mu \mathrm{M} \beta$-mercaptoethanol, $2 \mathrm{mM}$ L-glutamine, $1 \mathrm{mM}$ sodium pyruvate, $100 \mu \mathrm{M}$ nonessential amino acids) at a concentration of $2 \times 10^{6} \mathrm{cells} / \mathrm{ml}$.

Enrichment of HSPCs by lineage depletion. For enrichment of HSPCs, 8-week-old C57B//6 wild-type mice (Harlan Laboratories, Roßdorf, Germany) were killed and bone marrow was prepared from hind legs (femur and tibia), fore legs (humerus), hips (ilium) and vertebral column (columna vertebralis) by crushing bones in RPMI-1640 medium (Sigma-Aldrich) supplemented with 2\% FCS. To perform lineage depletion, bone marrow cells were incubated on ice for $40 \mathrm{~min}$ with rat monoclonal antibodies against common epitopes expressed on mature blood and bone marrow cells (CD11b (M1/70), Gr-1 (RB6.8C5), CD4 (GK1.5), CD8a (53.6.7), Ter119 (Ter119) and B220 (RA3-6B2)). Subsequently, cells were washed and incubated for $15 \mathrm{~min}$ on ice with anti-rat IgG-coated Dynabeads $(4.5 \mu \mathrm{m}$ supermagnetic polystyrene beads, Invitrogen, Darmstadt, Germany), $1 \mathrm{ml}$ of beads per $3 \times 10^{8}$ bone marrow cells. Cells expressing lineage markers were depleted using a magnet and the remaining lineage-negative cells were isolated and washed. To provide optimal conditions for HSPCs in downstream experiments, lineage-negative hematopoietic stem and progenitorenriched cells were cultured in StemPro-34 serum-free medium (Invitrogen) supplemented with nutrient supplement (Invitrogen) as well as recombinant TPO ( $50 \mathrm{ng} / \mathrm{ml}$; Peprotech, Hamburg, Germany), SCF (50 ng/ml; Peprotech) and Flt3 ligand (50 ng/ml; Peprotech).

Knockdown experiments. The siRNAs specific for p53 mRNA are (5'-GGUGAACCUUAGUACCUAAtt-3' or 5'-GUAAUCUACUGGGACGGAAtt-3'; Applied Biosystems, Darmstadt, Germany). $1.5 \times 10^{7}$ human peripheral blood $\mathrm{T}$ cells were transfected with $2 \mu \mathrm{M}$ of $p 53$ siRNA or of scrambled siRNA (Qiagen, Hilden, Germany) using Amaxa Human T Cell Nucleofector Kit (Lonza, Basel, Switzerland) according to the manufacturer's instructions. The Amaxa Nucleofector program U-014 was used for transfection.

Determination of DNA damage. DNA damage was determined by quantification of $\gamma-\mathrm{H} 2 \mathrm{AX}$ foci formation and by alkaline single-cell gel electrophoresis assay (comet assay). For $\gamma-\mathrm{H} 2 \mathrm{AX}$ staining, cells were treated as indicated, fixed in $3 \%$ formaldehyde and permeabilized in $90 \%$ methanol. 
Following storage at $-20^{\circ} \mathrm{C}$ overnight, cells were incubated with mouse serum to block unspecific binding and stained with antibody directed against $\gamma$-H2AX (AlexaFluor 488-coupled, 2F3; BioLegend, Fell, Germany), or with isotype control antibody (AlexaFluor 488-coupled; BioLegend). The amount of $\gamma-\mathrm{H} 2 \mathrm{AX}$ foci formation was determined by FACS measurement. Cell aliquots were taken and confocal microscopy was carried out to visualize Etoposide-induced $\gamma-\mathrm{H} 2 \mathrm{AX}$ foci formation. Nuclei were stained with DAPI mounting medium (Dianova, Hamburg, Germany). Comet assays were carried out as previously described. ${ }^{59}$ Briefly, electrophoresis of cellular genomic DNA was performed under alkaline conditions at $4^{\circ} \mathrm{C}$. The amount of DNA damage was measured by 'Olive Tail Moment'. Analysis of cellular DNA damage was carried out by fluorescence microscopy, using a fully automated cell scanning system Metafer-4 (Metasystems, Altlußheim, Germany).

RNA isolation and quantitative real-time PCR. Total cellular RNA was isolated using the RNeasy Mini Kit (Qiagen) according to the manufacturer's instructions. Reverse Transcription of RNA into CDNA was carried out by use of the High Capacity cDNA reverse transcription kit (Applied Biosystems). Quantitative real-time PCR was performed with an ABI Prism 7500 standard qRT-PCR cycler (Applied Biosystems) following the incorporation of SYBR Green. Reactions were carried out in triplicate. Relative gene expression levels were determined by normalization to the expression level of the housekeeping gene HPRT1. The $\triangle \Delta \mathrm{Ct}$ method ${ }^{60}$ was used to calculate fold expression levels. The following primers were used: HPRT1 (forward: $5^{\prime}$-TGACACTGGCAAAACAAT GCA-3', reverse: $5^{\prime}$-GGTCCTTTTCACCAGCAAGCT-3'), BBC3 (PUMA) (forward: 5'-GAAGAGCAAATGAGCCAAACG-3', reverse: $5^{\prime}$-GGAGCAACCGGCAAACG-3'), MDM2 (forward: 5'-ACCTCACAGATTCCAGCTTCG-3', reverse: 5'-TTTCATAG TATAAGTGTCTTTTT-3'), FAS (forward: 5'-AGCTTGGTCTAGAGTGAAAA-3', reverse: $5^{\prime}$-GAGGCAGAATCATGAGATAT-3'), BAX (forward: $5^{\prime}$-GCTGTTG GGCTGGATCCAAG-3', reverse: 5'-TCAGCCCATCTTCTTCCAGA-3'), BCL2L11 (BIM) (forward: 5'-ATCCCCGCTTTTCATCTTTA-3', reverse: 5'-AGGACTTG GGGTTTGTGTTG-3'), TP53 (forward: 5'-TCAACAAGATGTTTTGCCAACTG -3', reverse: $5^{\prime}$-ATGTGCTGTGACTGCTTGTAGATG $-3^{\prime}$ ).

\section{Conflict of Interest}

The authors declare no conflict of interest.

Acknowledgements. This work was supported by the Deutsches Konsortium für Translationale Krebsforschung (DKTK) and the Helmholtz Alliance on Immunotherapy of Cancer. We thank Iqbal S, Mülbaier $\mathrm{H}$ and Gliniorz R for technical assistance. We thank Proksch $\mathrm{P}$ for providing different Roc-A derivatives. We also thank Liu H-K (German Cancer Research Center, Heidelberg, Germany) for kindly providing $p 53^{-1-}$ mice. Moreover, we thank Rampoldi $F$ for critical discussion of the data.

1. Roos WP, Kaina B. DNA damage-induced cell death: from specific DNA lesions to the DNA damage response and apoptosis. Cancer Lett 2013; 332: 237-248.

2. Crawford J, Dale DC, Lyman GH. Chemotherapy-induced neutropenia: risks, consequences, and new directions for its management. Cancer 2004; 100: 228-237.

3. Sinkule JA. Etoposide: a semisynthetic epipodophyllotoxin. Chemistry, pharmacology, pharmacokinetics, adverse effects and use as an antineoplastic agent. Pharmacotherapy 1984; 4: 61-73.

4. Mackall C, Fleisher T, Brown M, Magrath I, Shad A, Horowitz M et al. Lymphocyte depletion during treatment with intensive chemotherapy for cancer. Blood 1994; 84: 2221-2228.

5. Bodey GP, Buckley M, Sathe YS, Freireich EJ. Quantitative relationships between circulating leukocytes and infection in patients with acute leukemia. Ann Intern Med 1966; 64: $328-340$.

6. Bonner WM, Redon CE, Dickey JS, Nakamura AJ, Sedelnikova OA, Solier $S$ et al. GammaH2AX and cancer. Nat Rev Cancer. 2008; 8: 957-967.

7. Goel HC, Prasad J, Singh S, Sagar RK, Agrawala PK, Bala M et al. Radioprotective potential of an herbal extract of Tinospora cordifolia. J Radiat Res 2004; 45: 61-68.

8. Mehendale SR, Aung HH, Yin J-J, Lin E, Fishbein A, Wang C-Z et al. Effects of antioxidant herbs on chemotherapy-induced nausea and vomiting in a rat-pica model. Am J Chin Med 2004; 32: 897-905

9. Lee SE, Oh H, Yang JA, Jo SK, Byun MW, Yee ST et al. Radioprotective effects of two traditional Chinese medicine prescriptions: si-wu-tang and si-jun-zi-tang. Am J Chin Med 1999; 27: 387-396.
10. Lam W, Bussom S, Guan F, Jiang Z, Zhang W, Gullen EA et al. The four-herb Chinese medicine PHY906 reduces chemotherapy-induced gastrointestinal toxicity. Sci TransI Med 2010; 2: 45ra59.

11. Farrell MP, Kummar S. Phase I/IIA randomized study of PHY906, a novel herbal agent, as a modulator of chemotherapy in patients with advanced colorectal cancer. Clin Colorectal Cancer 2003; 2: 253-256.

12. Chan KKL, Yao TJ, Jones B, Zhao JF, Ma FK, Leung CY et al. The use of Chinese herbal medicine to improve quality of life in women undergoing chemotherapy for ovarian cancer: a double-blind placebo-controlled randomized trial with immunological monitoring. Ann Oncol 2011; 22: 2241-2249.

13. Lu King M, Chiang C-C, Ling H-C, Fujita E, Ochiai M, McPhail AT. X-Ray crystal structure of rocaglamide, a novel antileulemic $1 \mathrm{H}$-cyclopenta[b]benzofuran from Aglaia elliptifolia. $J$ Chem Soc Chem Commun 1982; 20: 1150-1151.

14. Kim S, Salim AA, Swanson SM, Kinghorn AD. Potential of cyclopenta[b]benzofurans from Aglaia species in cancer chemotherapy. Anticancer Agents Med Chem 2006; 6: 319-345.

15. Ebada SS, Lajkiewicz N, Porco JA, Li-Weber M, Proksch P. Chemistry and biology of rocaglamides ( $=$ flavaglines) and related derivatives from aglaia species (meliaceae). Prog Chem Org Nat Prod 2011; 94: 1-58.

16. Ohse T, Ohba S, Yamamoto T, Koyano T, Umezawa K. Cyclopentabenzofuran lignan protein synthesis inhibitors from Aglaia odorata. J Nat Prod 1996; 59: 650-652.

17. Lee SK, Cui B, Mehta RR, Kinghorn AD, Pezzuto JM. Cytostatic mechanism and antitumor potential of novel $1 \mathrm{H}$-cyclopenta[b]benzofuran lignans isolated from Aglaia elliptica. Chem Biol Interact 1998; 115: 215-228.

18. Polier G, Neumann J, Thuaud F, Ribeiro N, Gelhaus C, Schmidt $\mathrm{H}$ et al. The natural anticancer compounds rocaglamides inhibit the Raf-MEK-ERK pathway by targeting prohibitin 1 and 2. Chem Biol 2012; 19: 1093-1104.

19. Sadlish H, Galicia-Vazquez G, Paris CG, Aust T, Bhullar B, Chang $L$ et al. Evidence for a functionally relevant rocaglamide binding site on the elF4A-RNA complex. ACS Chem Biol 2013; 8: 1519-1527.

20. Vousden KH, Lu X. Live or let die: the cell's response to p53. Nat Rev Cancer 2002; 2: 594-604.

21. Roos WP, Kaina B. DNA damage-induced cell death by apoptosis. Trends Mol Med 2006: 12: 440-450.

22. Rogakou EP, Pilch DR, Orr AH, Ivanova VS, Bonner WM. DNA double-stranded breaks induce histone H2AX phosphorylation on serine 139. J Biol Chem 1998; 273: 5858-5868.

23. Lowe SW, Ruley HE, Jacks T, Housman DE. p53-dependent apoptosis modulates the cytotoxicity of anticancer agents. Cell 1993; 74: 957-967.

24. Vassilev LT, Vu BT, Graves B, Carvajal D, Podlaski F, Filipovic $Z$ et al. In vivo activation of the p53 pathway by small-molecule antagonists of MDM2. Science 2004; 303: 844-848.

25. Egle A, Harris AW, Bouillet P, Cory S. Bim is a suppressor of Myc-induced mouse B cell leukemia. Proc Natl Acad Sci USA 2004; 101: 6164-6169.

26. Feuerborn A, Möritz C, Von Bonin F, Dobbelstein M, Trümper L, Stürzenhofecker B et al. Dysfunctional p53 deletion mutants in cell lines derived from Hodgkin's lymphoma. Leuk Lymphoma 2006; 47: 1932-1940.

27. Cheng J, Haas M. Frequent mutations in the p53 tumor suppressor gene in human leukemia T-cell lines. Mol Cell Biol 1990; 10: 5502-5509.

28. Zhu JY, Giaisi M, Köhler R, Müller WW, Mühleisen A, Proksch P et al. Rocaglamide sensitizes leukemic $T$ cells to activation-induced cell death by differential regulation of CD95L and C-FLIP expression. Cell Death Differ 2009; 16: 1289-1299.

29. Forbes S, Clements J, Dawson E, Bamford S, Webb T, Dogan A et al. Cosmic 2005. Br J Cancer 2006; 94: 318-322.

30. Zhou M, Gu L, Yeager AM, Findley HW. Sensitivity to Fas-mediated apoptosis in pediatric acute lymphoblastic leukemia is associated with a mutant p53 phenotype and absence of Bcl-2 expression. Leukemia 1998; 12: 1756-1763.

31. Jia LQ, Osada M, Ishioka C, Gamo M, Ikawa S, Suzuki T et al. Screening the p53 status of human cell lines using a yeast functional assay. Mol Carcinog 1997; 19: 243-253.

32. Barbarotto E, Corallini F, Rimondi E, Fadda R, Mischiati C, Grill V et al. Differential effects of chemotherapeutic drugs versus the MDM-2 antagonist nutlin-3 on cell cycle progression and induction of apoptosis in SKW6.4 lymphoblastoid B-cells. J Cell Biochem 2008; 104: 595-605.

33. Fujita T, Kiyama M, Tomizawa Y, Kohno T, Yokota J. Comprehensive analysis of p53 gene mutation characteristics in lung carcinoma with special reference to histological subtypes. Int J Oncol 1999; 15: 927-934.

34. Marine J-C, Lozano G. Mdm2-mediated ubiquitylation: p53 and beyond. Cell Death Differ 2010; 17: 93-102.

35. Lee JT, Gu W. The multiple levels of regulation by p53 ubiquitination. Cell Death Differ 2010; 17: 86-92.

36. Takagi M, Absalon MJ, McLure KG, Kastan MB. Regulation of $\mathrm{p} 53$ translation and induction after DNA damage by ribosomal protein L26 and nucleolin. Cell 2005; 123: 49-63.

37. Gajjar M, Candeias MM, Malbert-Colas L, Mazars A, Fujita J, Olivares-lllana V et al. The p53 mRNA-Mdm2 interaction controls Mdm2 nuclear trafficking and is required for p53 activation following DNA damage. Cancer Cell 2012; 21: 25-35.

38. Bleumink $M$, Köhler $R$, Giaisi $M$, Proksch $P$, Krammer PH, Li-Weber $M$. Rocaglamide breaks TRAlL resistance in HTLV-1-associated adult T-cell leukemia/ lymphoma by translational suppression of c-FLIP expression. Cell Death Differ 2011; 18: 362-370. 
39. Cencic R, Carrier M, Galicia-Vázquez G, Bordeleau M-E, Sukarieh R, Bourdeau A et al. Antitumor activity and mechanism of action of the cyclopenta[b]benzofuran, silvestrol. PLoS One 2009; 4: e5223.

40. Lowe SW, Schmitt EM, Smith SW, Osborne BA, Jacks T. p53 is required for radiationinduced apoptosis in mouse thymocytes. Nature 1993; 362: 847-849.

41. Westphal $\mathrm{CH}$, Hoyes KP, Canman CE, Christine E, Leder P, Huang X et al. Loss of atm Radiosensitizes Multiple p53 Null Tissues. Cancer Res 1998; 58: 5637-5639.

42. Vogelstein B, Lane D, Levine AJ. Surfing the p53 network. Nature 2000; 408: 307-310.

43. Martinez-Rivera M, Siddik ZH. Resistance and gain-of-resistance phenotypes in cancers harboring wild-type p53. Biochem Pharmacol 2012; 83: 1049-1062.

44. Zhu JY, Lavrik IN, Mahlknecht U, Giaisi M, Proksch P, Krammer PH et al. The traditional Chinese herbal compound rocaglamide preferentially induces apoptosis in leukemia cells by modulation of mitogen-activated protein kinase activities. Int J Cancer2007; 121: 1839-1846.

45. Balmanno K, Cook SJ. Tumour cell survival signalling by the ERK1/2 pathway. Cell Death Differ 2009; 16: 368-377.

46. Wang X, Jiang X. Mdm2 and MdmX partner to regulate p53. FEBS Lett 2012; 586: 1390-1396.

47. Christophorou MA, Ringshausen I, Finch AJ, Swigart LB, Evan GI. The pathological response to DNA damage does not contribute to p53-mediated tumour suppression. Nature 2006; 443: 214-217.

48. Hinkal G, Parikh N, Donehower LA. Timed somatic deletion of p53 in mice reveals age-associated differences in tumor progression. PLoS One 2009; 4: e6654.

49. Komarov PGA. Chemical inhibitor of p53 that protects mice from the side effects of cancer therapy. Science 1999; 285: 1733-1737.

50. Li T, Kon N, Jiang L, Tan M, Ludwig T, Zhao Y et al. Tumor suppression in the absence of p53-mediated cell-cycle arrest, apoptosis, and senescence. Cell 2012; 149: 1269-1283.

51. Brady CA, Jiang D, Mello SS, Johnson TM, Jarvis LA, Kozak MM et al. Distinct p53 transcriptional programs dictate acute DNA-damage responses and tumor suppression. Cell 2011; 145: 571-583.

52. Bernard Y, Ribeiro N, Thuaud F, Türkeri G, Dirr R, Boulberdaa M et al. Flavaglines alleviate doxorubicin cardiotoxicity: implication of Hsp27. PLoS One 2011; 6: e25302.
53. Ribeiro N, Thuaud F, Bernard Y, Gaiddon C, Cresteil T, Hild A et al. Flavaglines as potent anticancer and cytoprotective agents. J Med Chem 2012; 55: 10064-10073.

54. Jacobs WB, Kaplan DR, Miller FD. The p53 family in nervous system development and disease. J Neurochem 2006; 97: 1571-1584.

55. Trimmer PA, Smith TS, Jung AB, Bennett JP. Dopamine neurons from transgenic mice with a knockout of the p53 gene resist MPTP neurotoxicity. Neurodegeneration 1996; 5: 233-239.

56. Fahrig T, Gerlach I, Horva E. A synthetic derivative of the natural product Rocaglaol is a potent inhibitor of cytokine-mediated signaling and shows neuroprotective activity in vitro and in animal models of Parkinson's Disease and traumatic brain injury. Mol Pharmacol 2005; 67: 1544-1555.

57. Klas C, Debatin KM, Jonker RR, Krammer PH. Activation interferes with the APO-1 pathway in mature human T cells. Int Immunol 1993; 5: 625-630.

58. Nicoletti I, Migliorati G, Pagliacci MC, Grignani F, Riccardi C. A rapid and simple method for measuring thymocyte apoptosis by propidium iodide staining and flow cytometry. $\mathrm{J}$ Immunol Methods 1991; 139: 271-279.

59. Greve B, Bölling T, Amler S, Rössler U, Gomolka M, Mayer C et al. Evaluation of different biomarkers to predict individual radiosensitivity in an inter-laboratory comparison-lessons for future studies. PLoS One 2012; 7: e47185.

60. Pfaffl MW. A new mathematical model for relative quantification in real-time RT-PCR. Nucleic Acids Res 2001; 29: e45.

(c) (1) $(\Theta)$ Cell Death and Disease is an open-access journal published by Nature Publishing Group. This work is licensed under a Creative Commons Attribution-NonCommercialNoDerivs 3.0 Unported License. To view a copy of this license, visit http://creativecommons.org/licenses/by-nc-nd/3.0/

Supplementary Information accompanies this paper on Cell Death and Disease website (http://www.nature.com/cddis) 